\section{Resistant Ribonuclease Activity in Preparations of Total RNA Extracted from Artiodactyl Brain with GITC}

BioTechniques 34:920-924 (May 2003)

The protocol of Chomczynski and Sacchi (1) constitutes an established method widely used for extracting total RNA from many mammalian species. In general, this method produces goodquality total RNA suitable for various techniques such as Northern blot, RT$\mathrm{PCR}$, or RNase mapping. The combined inhibitory effect of both phenol and guanidium isothiocyanate (GITC) allows inactivation of most ribonuclease activity during RNA isolation. RNA quality is usually tested in the following three ways: visualization of $18 \mathrm{~S}$ and $28 \mathrm{~S}$ ribosomal RNA with agarose gel electrophoresis, detection of a particular mRNA expression by RT-PCR, and the RNA $A_{260 / 280}$ ratio, which gives information about protein contamination. However, in our experiments, a residual degrading activity in ovine RNA prepared with the Chomczynski and Sacchi method has been detected. This degradation was not observed when RNA was dissolved in water, and the controls described above gave correct results. The degradation occurred at a later stage when RNA was incubated in an enzyme buffer such as DNase I buffer, reverse transcriptase buffer, or in vitro transcription buffer.

Brain (hypothalamus and cortex) and liver total RNA were extracted from frozen artiodactyl and rodent tissues $\left(-70^{\circ} \mathrm{C}\right)$ using the Chomzynski and Sacchi method (1). Briefly, tissue was homogenized at ambient temperature or at $4^{\circ} \mathrm{C}$ in a denaturing solution (Solution D) composed of 4 M GITC; 25 $\mathrm{mM}$ sodium citrate, $\mathrm{pH} 7.0 ; 0.5 \%$ sarcosyl; $0.1 \mathrm{M} \beta$-mercaptoethanol. Onetenth volume $2 \mathrm{M}$ sodium acetate, $\mathrm{pH}$ 4.0, 1 volume phenol, and 0.2 volume choroform:isoamyl alcohol mixture (49:1) were successively added. The mixture was vigorously shaken and left for $15 \mathrm{~min}$ on ice. After centrifuging at $11000 \times g$ for $20 \mathrm{~min}$, the aqueous phase was mixed with one volume of isopropanol. The precipitated RNA was pelleted by centrifugation at $11000 \times g$ for $30 \mathrm{~min}$ and resuspended in Solution D. After a second centrifugation, the pellet was rinsed with $75 \%$ ethanol and dissolved in Milli-Q ${ }^{\circledR}$ water (Millipore S.A., St. Quentin Yvelines, France) (2).

Ten micrograms of RNA were treated with proteinase $\mathrm{K}(50 \mu \mathrm{g} / \mathrm{mL}$ final in $10 \mathrm{mM}$ Tris- $\mathrm{HCl}, \mathrm{pH} 7.5 ; 5 \mathrm{mM}$ EDTA; $0.5 \% \mathrm{SDS}$ ) for $30 \mathrm{~min}$ at $37^{\circ} \mathrm{C}$ and then subjected to one phenol:chloroform extraction, followed by two chloroform extractions and ethanol precipitation with sodium acetate. RNA was dissolved in Milli-Q water. Ten micrograms of untreated RNA and proteinase K-treated RNA were incubated in either Milli-Q water or enzyme buffer for $30 \mathrm{~min}$ at $37^{\circ} \mathrm{C}$ and recovered by ethanol precipitation. After centrifugation, the pellet was resuspended in a denaturing loading buffer, and RNA was separated on $1 \%$ agarose gel containing formaldehyde and visualized with ethidium bromide staining.

The electrophoresis on the denaturing gel in Figure 1A showed that the method of Chomczynski and Sacchi leads to the preparation of intact ovine hypothalamus RNA, when in Milli-Q water solution, even after $30 \mathrm{~min}$ incubation at $37^{\circ} \mathrm{C}$ (lanes 1 and 2). The $\mathrm{A}_{260 / 280}$ ratio was generally within an acceptable range (1.6-1.8), considering the slightly acidic $\mathrm{pH}$ of the solution after RNA dissolution in water (3). When incubated in DNase I buffer (33 mM Tris-acetate, pH 7.8, 66 mM potassium acetate, $10 \mathrm{mM}$ magnesium acetate, $0.5 \mathrm{mM}$ DTT; BD Biosciences Clontech, Palo Alto, CA, USA) for 10, 20 , and $30 \mathrm{~min}$ at $37^{\circ} \mathrm{C}$ (lanes 3-5), RNA was detected as smearing with total disappearance of the $18 \mathrm{~S}$ and $28 \mathrm{~S}$ RNA (lanes 4 and 5). This degradation did not occur when the RNA preparation was first subjected to treatment with proteinase K. Proteinase K-treated RNA retained its integrity when incubated for $30 \mathrm{~min}$ at $37^{\circ} \mathrm{C}$ in DNase I buffer (lane 10). Moreover, this degrading activity disappeared when proteinase K-untreated RNA was incubated in DNase I buffer in the presence of RNase inhibitor (Rnasin ${ }^{\circledR}$; Promega France, Charbonniéres, France) (lane
6). This may mean that the degradation is due to the action of a ribonuclease co-purified with RNA. The same pattern was observed in preparations of bovine and porcine brain RNA (Table 1), from which it could be concluded that this degrading activity may be found in artiodactyl species. This activity is not restricted to the hypothalamus, since we have also found it in cortex RNA preparations (Table 1).

In contrast, we did not observe any degradation in rodent brain RNA, even when incubated in DNase I buffer at $37^{\circ} \mathrm{C}$. The migration pattern of rat RNA on denaturing agarose gel showed profiles of intact RNA from the hypothalamus or cortex, incubated in either Milli-Q water or DNase I buffer (Figure 1B, lanes 1-4). The same result was obtained with mouse RNA (data not shown). This showed that the residual activity depicted above is species-specific in the brain. While it is found co-purified with RNA from artiodactyl species, no degradation can be detected in rodent RNA preparation when incubated with DNase I buffer at $37^{\circ} \mathrm{C}$ (results are summarized in Table 1). In sheep and rodents, we observed no difference between males and females (Table 1).

To eliminate the latent degrading activity, two additional phenol:chloroform extractions were performed on the aqueous phase before isopropanol precipitation. This modification, intended to remove some residual proteins from preparations, did not alter RNA integrity when incubated in Milli-Q water (Figure 2A, lane 2). Surprisingly, the degrading activity was resistant to the three successive phenol:chloroform extractions (Figure 2A, lane 3).

The degradation was also observed when sheep RNA was incubated in a reverse transcriptase buffer $(50 \mathrm{mM}$ Tris- $\mathrm{HCl}, \mathrm{pH} 8.3,75 \mathrm{mM} \mathrm{KCl,} 3 \mathrm{mM}$ $\mathrm{MgCl}_{2}$; SuperScript II ${ }^{\circledR}$; Invitrogen S.A.R.L., Cergy Pontoise, France) and in an in vitro transcription buffer (40 $\mathrm{mM}$ Tris- $\mathrm{HCl}, \mathrm{pH} 8.0,8 \mathrm{mM} \mathrm{MgCl}_{2}, 2$ $\mathrm{mM}$ spermidine, $50 \mathrm{mM} \mathrm{NaCl}$, Stratagene, La Jolla, CA, USA) (Figure 2B, lanes 3 and 5). The integrity of proteinase K-treated RNA after incubation in these two buffers demonstrated that there was no exogenous RNase contamination during the experiment (lanes 
Table 1. Ribonuclease Activity in Total RNA Isolated from Hypothalamus and Cortex of Artiodactyl and Rodent Species

\begin{tabular}{|lccccc|}
\hline & \multicolumn{2}{c}{ Hypothalamus } & & \multicolumn{2}{c|}{ Cortex } \\
\cline { 2 - 5 } & $\begin{array}{l}\text { + DNase I } \\
\text { Buffer }\end{array}$ & $\begin{array}{c}\text { Milli-Q } \\
\text { Water }\end{array}$ & & $\begin{array}{c}\text { + DNase I } \\
\text { Buffer }\end{array}$ & $\begin{array}{c}\text { Milli-Q } \\
\text { Water }\end{array}$ \\
\hline Ram & + & - & & + & - \\
Ewe & + & - & + & - \\
Cow & + & - & & + & - \\
Sow & + & - & & + & - \\
Female rat & - & - & - & - \\
Male rat & - & - & - & - \\
Female mouse & - & - & - & - \\
Male mouse & - & & & \\
(+) presence or $(-)$ absence of RNase activity & &
\end{tabular}

4 and 6). The components common to the three buffers used are Tris and magnesium. However, either incubation of RNA in $40 \mathrm{mM}$ Tris- $\mathrm{HCl}$, $\mathrm{pH} 8.0$, or incubation in $10 \mathrm{mM} \mathrm{MgCl}_{2}$ alone did not bring about degradation of RNA (Figure 1A, lanes 7 and 8). The degradation was only observed when RNA is incubated with both components (lane 9). The ribonuclease activity needs magnesium ions and appropriate $\mathrm{pH}$. Accordingly, the degradation could occur during any enzymatic reaction providing these conditions are present.

We also looked for the presence of the degrading activity in sheep liver RNA preparation. Figure $2 \mathrm{C}$ (lanes $1-3)$ shows that the ribonuclease activi- ty is also present in ewe liver RNA and is not restricted to the brain. The activity was detected in ram liver but not in female rat liver (data not shown).

The method of Chomczynski and Sacchi has often been modified to eliminate ribonuclease activity during preparation of RNA from particular organisms or tissues (4-6). Degradation sometimes occurs during RNA extraction from sheep brain tissues leading to degraded RNA solubilized in water, even without subsequent treatment (data not shown). In our hands, two phenol:chloroform extractions added to our protocol always allowed undegraded brain RNA from artiodactyl species to be obtained when ultimately dissolved in water without change in RNA quality. However, to the best of our knowledge, we are the first to describe a delayed activity that is expressed only under particular saline and $\mathrm{pH}$ conditions and that is not picked up by the usual testing of RNA integrity, since RNA is almost always dissolved in water or in magnesium-free buffer. RT-PCR does not adequately estimate the RNA integrity, since amplification can occur on partially degraded RNA and, in this case, does not reflect the level of mRNA expression. Untreated RNA used in RT-PCR instead of proteinase K-treated RNA dramatically decreased the yield of amplified products (data not shown), showing that the degrading activity altered mRNA integrity. Recent quantitative techniques of molecular biology, such as real-time PCR, quantitative RT-PCR, subtractive and suppressive hybridization, differential display, or micro/ macroarray hybridization, particularly require RNA preparation free of all ribonuclease activity. In these methods, RNA is subjected to enzymatic reactions, such as reverse transcription and DNase I treatment that in most cases are performed in magnesium-containing buffer at a $\mathrm{pH}$ between 7.0 and 8.0. Consequently, RNA preparations should be tested before any other utilization, by incubating them alone in the buffer used for the following enzymatic reaction at the appropriate temperature, to ensure the absence of a latent ribonuclease activity. Treatment with proteinase K elim-

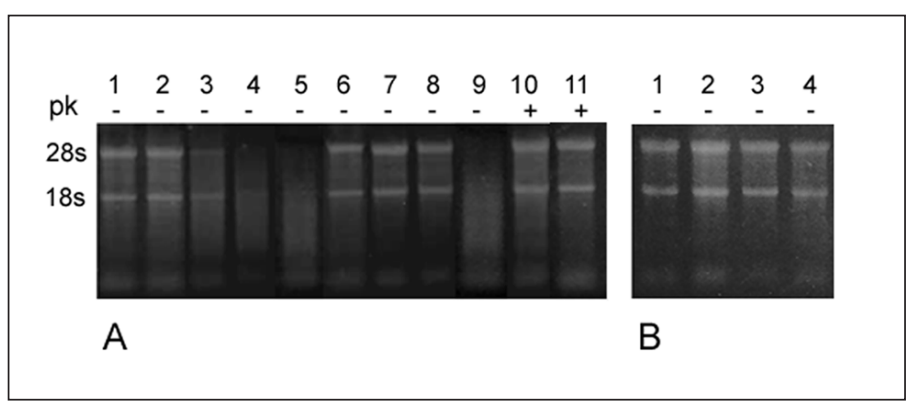

Figure 1. Effect of incubation in DNase I buffer on the integrity of total RNA isolated from ewe and rat tissues according to the method of Chomczynski and Sacchi. Total RNA was separated by electrophoresis on $1 \%$ agarose gel containing formaldehyde. A1-11, ewe hypothalamus; B1 and B2, rat hypothalamus; B3 and $\mathrm{B} 4$, rat cortex. pk (+): RNA treated with proteinase K; pk (-): untreated RNA. A1: in Milli-Q water without any treatment. A2, B1, and B3: in Milli-Q water at $37^{\circ} \mathrm{C}$ for 30 min. A3 and A4: in DNase I buffer at $37^{\circ} \mathrm{C}$ for 10 and 20 min respectively. $\mathrm{A} 5, \mathrm{~A} 10, \mathrm{~B} 2$, and B4: in DNase I buffer at $37^{\circ} \mathrm{C}$ for $30 \mathrm{~min}$. A6: in DNase I buffer with $20 \mathrm{U}$ Rnasin at $37^{\circ} \mathrm{C}$ for $30 \mathrm{~min}$. A7: in $40 \mathrm{mM}$ Tris- $\mathrm{HCl}$, pH 8.0 , at $37^{\circ} \mathrm{C}$ for $30 \mathrm{~min}$. A8: in $10 \mathrm{mM} \mathrm{MgCl}_{2}$ at $37^{\circ} \mathrm{C}$ for $30 \mathrm{~min}$. A9 and A11: in $40 \mathrm{mM}$ Tris- $\mathrm{HCl}$, $\mathrm{pH} 8.0,10 \mathrm{mM} \mathrm{MgCl}_{2}$, at $37^{\circ} \mathrm{C}$ for $30 \mathrm{~min}$.

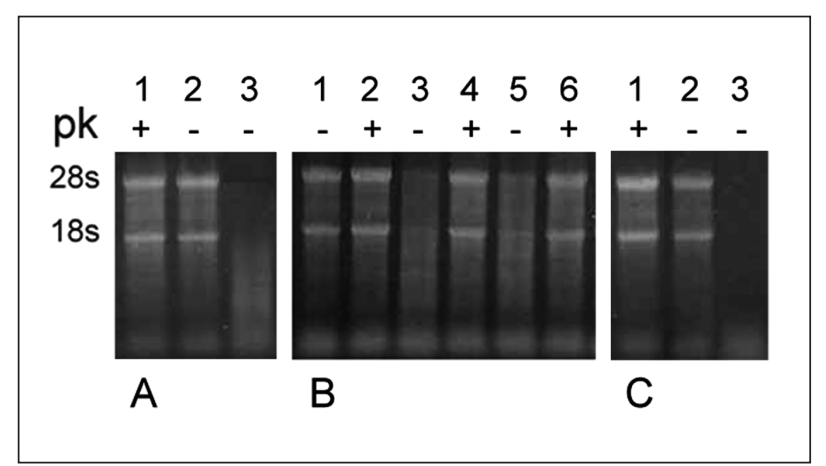

Figure 2. Ribonuclease activity in RNA isolated from ewe hypothalamus (A and B) and ewe liver (C). Total RNA was separated on 1\% agarose gel containing formaldehyde. Two phenol:chloroform extractions were added to the protocol of Chomczynski and Sacchi before isopropanol precipitation. pk (+): RNA treated with proteinase K; pk (-): untreated RNA. A2, B1, B2, and C2: in Milli-Q water at $37^{\circ} \mathrm{C}$ for $30 \mathrm{~min}$. $\mathrm{A} 1, \mathrm{~A} 3, \mathrm{C} 1$, and $\mathrm{C} 3$ : in DNase I buffer at $37^{\circ} \mathrm{C}$ for $30 \mathrm{~min}$. B3 and B4: in $1 \times$ SuperScript II reverse transcriptase buffer at $37^{\circ} \mathrm{C}$ for $30 \mathrm{~min} . \mathrm{B} 5$ and B6: in $1 \times$ RNA polymerase buffer at $37^{\circ} \mathrm{C}$ for $30 \mathrm{~min}$. 
inates the residual ribonuclease activity, although the effect of this treatment on the subsequent experiments should be checked. An inhibitor of RNase, such as Rnasin, can also be added to further enzymatic reactions.

This study has described a degrading activity in RNA preparations from ovine, bovine, and porcine brain and ovine liver. Further experiments on these species need to be undertaken to verify whether the ribonuclease activity is present in other tissues or not. RNA extracted according to protocols other than those of Chomczynski and Sacchi should also be tested in artiodactyls as well as in species from other orders.

\section{REFERENCES}

1.Chomczynski, P. and N. Sacchi. 1987. Single-step method of RNA isolation by acid guanidium thiocyanate-phenol-chloroform extraction. Anal. Biochem. 162:156-159.

2.Huang, Y.H., P. Leblanc, V. Apostolou, B. Steward, and R.B. Moreland. 1995. Comparison of Milli-Q ${ }^{\circledR}$ PF Plus water to DEPCtreated water in the preparation and analysis of RNA. BioTechniques 19:656-661.

3.Wilfinger, W.W., K. Mackey, and P. Chomczynski. 1997. Effect of $\mathrm{pH}$ and ionic strength on the spectrophotometric assessment of nucleic acid purity. BioTechniques 22:474-481.

4.Groppe, J.C. and D.E. Morse. 1993. Isolation of full-length RNA templates for reverse transcription from tissues rich in RNase and proteoglycans. Anal. Biochem. 210:337-343.

5.Santokh, S.G., R.A. Aubin, C.A. Bura, I.H.A. Curran, and T.I. Matula. 1996. Ensuring recovery of intact RNA from rat pancreas. Mol. Biotechnol. 6:359-362.

6.Gruffat, D., C. Piot, D. Durand, and D. Bauchart. 1996. Comparison of four methods for isolating large mRNA: apolipoprotein B mRNA in bovine and rat livers. Anal. Biochem. 242:77-83.

Address correspondence to Dr. Gilles Bruneau, UMR 6073 Physiologie de la Reproduction et des Comportements, (INRA) CNRS/Université François Rabelais de Tours), 37380 Nouzilly, France. e-mail: bruneau@tours.inra.fr

Received 23 December 2002; accepted 11 February 2003.

\section{Delphine Pillon and \\ Gilles Bruneau}

INRA/CNRS/Université

François Rabelais de Tours

Nouzilly, France

\section{Methylation Sensitivity of Restriction Enzymes Interacting with GATC Sites}

BioTechniques 34:924-930 (May 2003)

DNA methylation plays an important role in many species ranging from bacteria to man, by controlling the expression of genes and protection of the genome from selfish DNA like transposons and viruses $(1,2)$. In E. coli and other $\gamma$-proteobacteria, methylation of adenine residues (dam, DNA adenine methylation) occurs at GATC sites. It serves to discriminate between parental and daughter strand during postreplicative mismatch repair, to coordinate cell cycle, DNA replication, and to regulate gene expression $(2,3)$. It also controls the pathogenicity of different $\gamma$-proteobacteria $(4,5)$. To investigate the methylation state of DNA from various bacteria, archea as well as lower and higher eukaryotes, digestion of the DNA with GATC-interacting restriction enzymes is often used (6-13). In addition to its biological functions, dam methylation and GATC-specific restriction enzymes have several important applications in biotechnology and molecular biology. (i) One of the most commonly used methods for site directed mutagenesis employs a specific digestion of dam-methylated DNA by DpnI (14-18). In this application, DpnI is used to digest the template DNA after PCR, which almost completely removes the background of wild-type plasmid used as PCR template. (ii) Since dam methylation does not occur in eukaryotes, it can be used to follow the replication of bacterial DNA transfected into eukaryotic cells (19-27). (iii) Transcription factors can be fused to the dam methyltransferase and transfected into cells. The resulting pattern of dam methylation allows one to deduce the DNA binding specificity of the transcription factor $(28,29)$. In addition, the pattern of dam methylation in eukaryotic cells overexpressing the bacterial dam enzyme can be used to map the chromatin structure, because the dam methyltransferase is inhibited by nucleosomes (30-32).
To understand the biological processes related to dam methylation and to employ dam methylation for biotechnological purposes, characterization of the exact methylation status of target DNA is necessary. There are different tools to map methylated bases in DNA; one of the most commonly used methods is to digest the endogenous DNA with restriction enzymes, which are characterized with respect to their methylation sensitivity. Data on the methylation sensitivity (and many other important properties) of restriction enzymes are compiled in REBASE (http://rebase.neb.com/rebase/) (33). Unfortunately, methylation sensitivity was not easily available for some enzymes interacting with GATC sites, or inconsistent data were published (Table 1). Therefore, we decided to reinvestigate the methylation sensitivity of restriction enzymes acting on GATC sites with respect to the effects of adenine and cytosine methylation. Since we intended to distinguish between the effect of methylation of only one and both DNA strands, we chose modified oligonucleotides as substrates. Usage of synthetic substrates also ensures that complete methylation is present, which is not the case if enzymatically methylated DNA is used.

We used synthetic 19-mer oligonucleotide substrates (5'-CGCGGCCGGATCCCCGGGC-3') that differ in the methylation status of the GATC sequence being unmethylated, methylated in one strand of the DNA (hemimethylated), or methylated in both DNA strands (fully methylated). The HPLCpurified oligonucleotides were purchased from Thermohybaid (Heidelberg, Germany). One strand of each substrate was phosphorylated with T4PNK and $\left[\gamma_{-32}{ }^{32}\right]$ ATP and annealed to the other strand by heating to $75^{\circ} \mathrm{C}$ and slowly cooling to ambient temperature. By using hemimethylated substrates labeled in the unmethylated or methylated strand, we can distinguish between cutting of both strands and nicking of only one. DpnI, DpnII, and Sau3AI were from New England Biolabs (Beverly, MA, USA), NdeII from Sigma (St. Louis, MO, USA), and $M b o$ I from MBI Fermentas (Vilnius, Lithuania). For the cleavage reaction, different amounts of enzymes (0.01-20 U) and $30 \mathrm{nM}$ DNA 